http://jmscr.igmpublication.org/home/ ISSN (e)-2347-176x ISSN (p) 2455-0450

crossref DOI: https://dx.doi.org/10.18535/jmscr/v9i1.41

Journal Of Medical Science And Clinical Research IGM Publication An Official Publication of IGM Publication

\title{
Comparative Study of Response and Toxicities between Induction Chemotherapy Followed by Concurrent Chemoradiation versus Concurrent Chemoradiation Only in the Treatment of Locally Advanced Carcinoma Cervix (Stage IB2, IIB-IVA) \\ Authors
}

\section{Dr Jannatun Nisa ${ }^{1}$, Prof. Dr Qamruzzaman Chowdhury ${ }^{2}$, Dr Shahida Alam³,} Dr Kamrun Nahar Tania ${ }^{4}$

${ }^{1}$ MBBS, FCPS (Radiotherapy) Resident Surgeon, Department of Radiation oncology, Chittagong Medical College \& Hospital

${ }^{2}$ MBBC, FCPS, DMRT (Oncology and Radiotherapy), Ex Head of the Department, Radiation Oncology

Department, National Institute of Cancer Research \& Hospital (NICRH)

${ }^{3} \mathrm{MBBS}$, FCPS (Radiotherapy), Associate Professor, Department of Radiation oncology, National Institute of Cancer Research \& Hospital (NICRH)

${ }^{4}$ MBBS, MD (Radiation Oncology), Registrar, Department of Radiation Oncology, National Institute of Cancer Research \& Hospital (NICRH)

\begin{tabular}{l} 
Abstract \\
Background: In Bangladesh majority cases of carcinoma cervix being diagnosed in advanced stage. This \\
study was aimed to determine whether induction chemotherapy would improve disease control and \\
clinical outcome of patients with locally advanced cervical cancer undergoing radiotherapy. \\
Methods: A quasi experimental study was carried out among 60 patients of histologically proven locally \\
advanced carcinoma cervix patients at Radiation Oncology Department of National Institute of Cancer \\
Research \& Hospital, Dhaka from June 2016 to May 2017 . Patients were accrued to arm A and arm B \\
purposively to receive sequential chemotherapy followed by concurrent chemoradiation or \\
chemoradiation only. \\
Results: The mean age of the arm A patients was 49.1 (SD \pm 8.65$)$ years and that of the arm B patients \\
was 50.5 (SD \pm 7.99$)$ years. Majority of the study subjects were from middle economic class. Most of the \\
patients (arm a 50\% and arm B $73.3 \%$ were in stage IIB. Vaginal discharge (arm A 56.7\% vs. arm B \\
$60 \%)$, post-menopausal P/V bleeding (arm A $40 \%$ vs. arm B $43.3 \%$ and irregular p/v bleeding (arm A \\
$33.3 \%$ vs. arm B $43.3 \%)$ were leading complaints. In arm A 17 patients (56.7\%) showed complete \\
response where in arm B complete response was noticed in 20 patients (66.7\%); partial responses were \\
11 (36.7\%) and 10 (33.3\%) in the two arms respectively. No statistically significance was found between \\
these two arms (p=0.526). Different treatment related toxicities like anemia, vomiting, leucopenia, \\
enteritis, dermatitis were reported in the both arms which faded away with time. Most importantly there \\
were no significant difference across the two arms in this regard. \\
Conclusion: Induction chemotherapy followed by concurrent chemoradiation was non inferior in respect \\
to relieving symptoms and achieving complete response than concurrent chemoradiotherapy only in \\
treatment of locally advanced cervical carcinoma. \\
Keywords: Induction chemotherapy, concurrent chemo radiation, locally advanced carcinoma cervix. \\
\hline
\end{tabular}




\section{Introduction}

\section{Background}

Cervical cancer is the second most common cancer among women worldwide\& also in Bangladesh. ${ }^{1}$ It is most notable in the lower resource countries of sub-Saharan Africa. It is also the fourth most common cause of cancer death in women worldwide. ${ }^{1}$ Within the United States, an estimated 12900 new diagnoses of carcinoma cervix occurred \& an estimated 4100 women eventually die of the disease in $2015 .^{2}$

Carcinoma cervix appears to be very common in Bangladesh. Oral, breast and cervical cancer together constitute more than $43 \%$ of the female cancer burden in Bangladesh. ${ }^{3}$ The majority of the cases are diagnosed when the disease is regional (2/3 ${ }^{\text {rd }}$ of all cases). ${ }^{4}$ In 2014 a total number of 18556 new patients attended the Out Patient Department (OPD) of National Institute of Cancer Research \& Hospital(NICRH). ${ }^{5}$ Out of 4983 female patients 894 (17.9\%) patients were suffering from cervical carcinoma \& carcinoma cervix ranked $4^{\text {th }}$ among top 10 malignancies in 2014 \& is the second most common cancer among female at NICRH. ${ }^{5}$

The higher incidence of cervical cancer is due to Human Papilloma Virus infection. HPV is associated with nearly all cases of cervical cancer. The most common subtypes are HPV-16 \& -18, which are found in $70 \%$ cases. ${ }^{6}$ Women who have coitus at a young age, who have multiple sex partners, have sexual partners with multiple partners, or who bear children at a young age or who are multipara are at increased risk. Cigarette smoking, prolonged oral contraceptive use and immune system alteration (HIV infection) also acts as risk factor for invasive cervical cancer. ${ }^{7}$

The commonest symptom of cervical cancer is metrorrhagia (intermenstrual bleeding), menorrhagia (heavier menstrual flow), postcoital bleeding and postmenopausal bleeding.. ${ }^{8}$

Most patients in developing countries present with advanced disease. Women with locally advanced cervical cancer have a higher rate of recurrence and worse survival than those with early stage disease. $^{9}$

The FIGO staging system is the most widely accepted staging system for carcinoma of the cervix. For practical purposes, cervical carcinoma is divided into four clinical stages-microinvasive carcinoma (stage $\mathrm{IA}_{1}$ ), early invasive carcinoma (stageIA $\mathrm{IB}_{1}$, some small stage IIA), locoregionally advanced carcinoma (stage $\mathrm{IB}_{2}$, IIB-IVA) and metastatic carcinoma (stage IVB). ${ }^{10}$ Radical Radiotherapy is the primary local treatment for most patients with locally advanced cervical carcinoma (inoperable). Radical radiotherapy consists of external beam radiotherapy plus intracavitary brachytherapy. ${ }^{7}$ Radiotherapy can be given sequentially after chemotherapy or concurrently with chemotherapy. So, multimodality treatment approach is needed for management of locally advanced cervical carcinoma.

The role of induction chemotherapy in cervical cancer has been a matter of investigation during the last 20 years. Since the $1^{\text {st }}$ publication by Friedlonder in 1983 on the use of primary chemotherapy in cervical cancer uncountable phase II trials \& several phase III trials have shown that those patients achieving a complete response after induction chemotherapy experience a significant improvement in overall survival. Some studies have shown that the survival rates between two groups are not significantly different. ${ }^{10}$

Large volume of primary tumor \& presence of micro metastatic disease at diagnosis are important reasons for treatment failure. ${ }^{11-12}$

Sometimes induction chemotherapy could compromise patient's tolerance of subsequent chemoradiation. $^{13}$ So this quasi-experimental study was aimed to compare the benefits of treatment \& toxicities in between induction chemotherapy followed by concurrent chemoradiation versus concurrent chemoradiation only in loco regionally advanced carcinoma cervix. 


\section{Materials and Methods}

This was a Quasi experimental study conducted in the department of Radiation Oncology, National Institute of Cancer Research and Hospital, Dhakafrom June 2016 to May 2017to compare the disease response, locoregional control and toxicities between induction chemotherapy followed by concurrent chemoradiation versus concurrent chemoradiotherapy in the treatment of locally advanced carcinoma cervix Patients with histologically \& radiologically proven locally advanced carcinoma cervix was selected from radiation oncology department of NICRH. Ethical approval was taken from the ethical committee of NICRH.

Sample size was calculated by following formula:

$$
n=\frac{p_{1}\left(1-p_{1}\right)+p_{2}\left(1-p_{2}\right)}{\left(p_{1}-p_{2}\right)^{2}} \times\left(Z_{\alpha}+Z_{\beta}\right)^{2}
$$

Here

$\mathrm{p} 1=50 \%(0.5)$

$\mathrm{p} 2=80 \%(0.8)$

$\mathrm{Z} \alpha=1.96$

$\mathrm{Z} \beta=1.64$

$\mathrm{n}=$ Sample size

$n=\frac{(0.5 \times 0.5)+(0.8 \times 0.2)}{(0.5-0.8) 2} \times(1.96+1.64) 2=60$

With $10 \%$ allowance for loss to follow up, final sample size $=60+6=66$.

Samples were collected through inclusion \& exclusion criteria. Inclusion criteria for this study was histologically proven diagnosed case of locally advanced carcinoma cervix, age $\leq 75$ years, Karnofsky performance status

$\geq 70$, clinically \& Radiologically FIGO stage IB2, IIB-IVA, histologies including squamous cell carcinoma adenocarcinoma, no history of prior radiotherapy.
Total study population was 60 among which 30 were in the in arm A and 30 were in the arm B.

In this study arm A got 2 cycles of induction chemotherapy with inj. Cisplatin $\left(75 \mathrm{mg} / \mathrm{m}^{2}\right)$ D1+inj. 5-FU $\left(1000 \mathrm{mg} / \mathrm{m}^{2}\right)$ D1-D3 every 21 day courses followed by concurrent chemoradiation 50 Gy in 25 fractions over 5 weeks with inj. cisplatin $40 \mathrm{mg} / \mathrm{m}^{2}$ weekly.In arm B patients got external beam radiotherapy 50 Gy in 25 fractions over 5 weeks with weekly inj. Cisplatin $40 \mathrm{mg} / \mathrm{m}^{2}$.Patient followed up at 4 weeks interval up to 3 months. Symptoms was graded \& recorded at the first day of radiotherapy \& at every patient visits during follow up time. In both Arm patients got intracavitary Brachytherapy with ${ }^{192}$ Iridium.

Outcome was measured in terms of symptom relief by VAS (visual analogue scale), tumor response by RECIST (Response evaluation criteria in solid tumor) \& toxicities by RTOG acute Radiation morbidity criteria.

Data was analyzed by using SPSS for windows V.19 software. Continuous data was presented as mean $+/$ - SD while categorical data was presented as frequency and percentage. To see the association between various variables Chi-squared test, Fisher's exact test, and t- test was used where applicable. $\mathrm{P}$ value of 0.05 or less was considered as significant. Result is presented in tables, figures and diagrams. $95 \%$ confidence intervals were calculated for these values. 


\section{JMSCR Vol||09||Issue||01||Page 216-224||January}

Flow chart at sequence of task of this quasi-experimental study is shown in the following flow chart diagram.

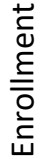
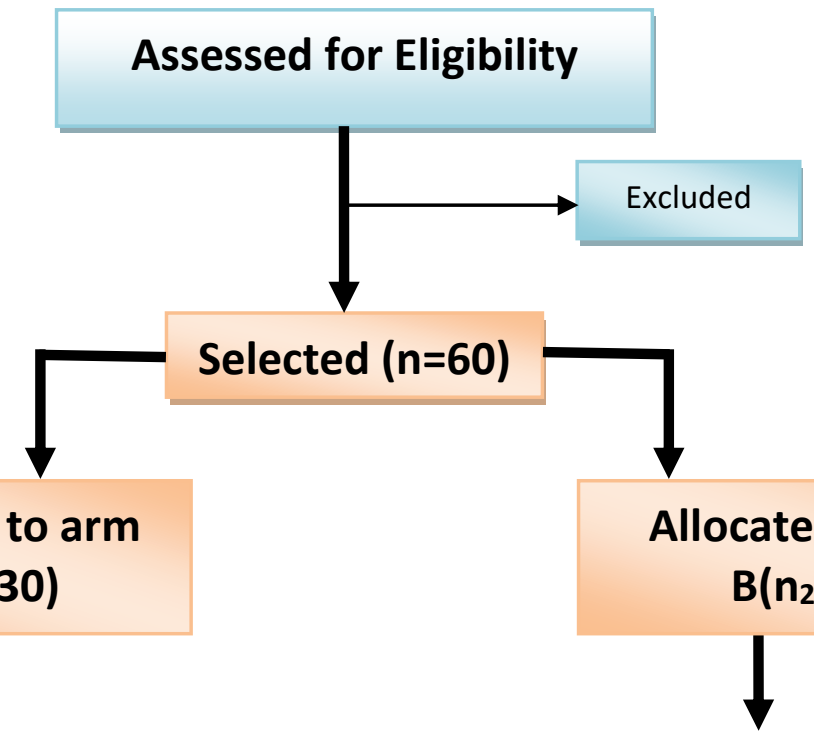

Selected $(n=60)$
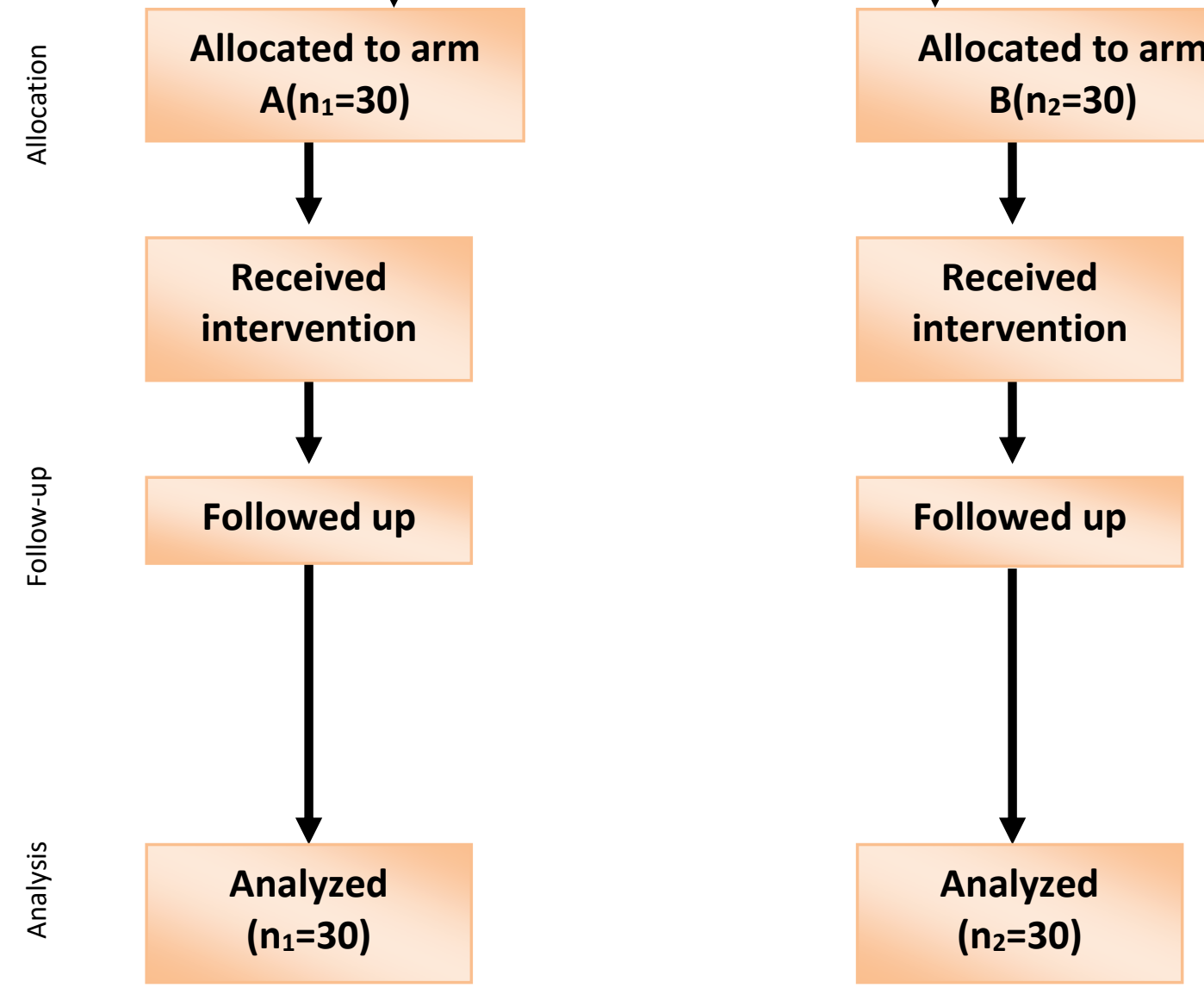


\section{Results}

This quasi experimental study was carried out to compare the disease response, locoregional control and toxicities between induction chemotherapy followed by concurrent chemoradiation and concurrent chemoradiotherapy in the treatment of locally advanced carcinoma cervix. From June 2016 to May 2017 total study population was 60 among which 30 were in the arm A and 30 were in the arm B.

Table I: Distribution of the patients by stage at diagnosis

\begin{tabular}{|c|c|c|c|c|}
\hline \multirow{2}{*}{$\begin{array}{l}\text { FIGO } \\
\text { stage at } \\
\text { diagnosis }\end{array}$} & \multicolumn{2}{|c|}{$\begin{array}{c}\begin{array}{c}\text { Category of } \\
\text { treatment }\end{array} \\
\end{array}$} & \multirow{2}{*}{$\begin{array}{c}\text { Fishe } \\
\text { r's } \\
\text { Exac } \\
\text { t Test }\end{array}$} & \multirow{2}{*}{$\begin{array}{c}p- \\
\text { value }\end{array}$} \\
\hline & $\begin{array}{c}\text { Sequenti } \\
\text { al CT* } \\
(\text { Arm A) }\end{array}$ & $\begin{array}{l}\text { Concurr } \\
\text { ent CRT } \\
\text { (Arm B) }\end{array}$ & & \\
\hline IIB & $15(50.0)$ & $22(73.3)$ & \multirow{5}{*}{4.853} & \multirow{5}{*}{0.161} \\
\hline IIIA & $3(10.0)$ & $0(0.0)$ & & \\
\hline IIIB & $10(33.3)$ & $7(23.3)$ & & \\
\hline IVA & $2(6.7)$ & $1(3.3)$ & & \\
\hline Total & $\begin{array}{c}30 \\
(100.0)\end{array}$ & $\begin{array}{c}30 \\
(100.0)\end{array}$ & & \\
\hline
\end{tabular}

"Followed by concurrent chemoradiotherapy

Most of the patients (arm A 50\% and arm B $73.3 \%$ ) were in FIGO stage IIB. The second leading stage was IIIB (arm A 33.3\% and arm B $23.3 \%$ ). However, no statistical significance was observed between arms in respect to stage $(p=0.161)$.

Table II: Distribution of the patients by clinical presentation

\begin{tabular}{lcccc}
\hline & \multicolumn{2}{c}{$\begin{array}{c}\text { Sequential } \\
\text { CT }\end{array}$} \\
& \multicolumn{2}{c}{$\begin{array}{c}\text { Concurrent } \\
\text { Chief complaints }\end{array}$} & \multicolumn{2}{c}{$\begin{array}{c}\text { CRT } \\
\text { (Arm B) }\end{array}$} \\
\cline { 2 - 6 } & $\mathbf{n}$ & $\%$ & n & \% \\
\hline Vaginal discharge & 17 & 56.7 & 18 & 60.0 \\
\hline $\begin{array}{l}\text { Post-menopausal P/V } \\
\text { bleeding }\end{array}$ & 12 & 40.0 & 13 & 43.3 \\
\hline Irregular p/v bleeding & 10 & 33.3 & 13 & 43.3 \\
\hline $\begin{array}{l}\text { Lower abdominal } \\
\text { pain }\end{array}$ & 15 & 50.0 & 6 & 20.0 \\
\hline $\begin{array}{l}\text { Excessive p/v } \\
\text { bleeding }\end{array}$ & 10 & 33.3 & 5 & 16.7 \\
\hline Post coital bleeding & 7 & 23.3 & 12 & 40.0 \\
\hline $\begin{array}{l}\text { Low back pain } \\
\text { Difficulty in } \\
\text { micturition }\end{array}$ & 6 & 20.0 & 3 & 10.0 \\
\hline
\end{tabular}

*Followed by concurrent chemoradiotherapy; multiple responses elicited
Table V: Distribution of the patients by toxicities

\begin{tabular}{lccccc}
\hline \multirow{2}{*}{ Parameters } & \multicolumn{6}{c}{$\begin{array}{c}\text { Sequential CT* Concurrent } \\
\text { (Arm A) }\end{array}$} & \multicolumn{2}{c}{ CT } \\
& (Arm B) & p-value \\
\cline { 2 - 5 } & $\mathbf{n}$ & $\mathbf{\%}$ & $\mathbf{n}$ & $\mathbf{\%}$ & \\
\hline Anaemia & & & & & \\
\hline $1^{\text {st }}$ follow-up & 21 & 70.0 & 17 & 56.7 & 0.284 \\
\hline $2^{\text {nd }}$ follow-up & 6 & 20.0 & 9 & 30.0 & 0.371 \\
\hline $3^{\text {rd }}$ follow-up & 2 & 6.7 & 4 & 13.3 & 0.614 \\
\hline $4^{\text {th }}$ follow-up & 1 & 3.3 & 0 & 0.0 & 0.492 \\
\hline
\end{tabular}

\section{Anorexia}

\begin{tabular}{lccccc}
\hline $1^{\text {st }}$ follow-up & 30 & 100.0 & 30 & 100.0 & 1.00 \\
\hline $2^{\text {nd }}$ follow-up & 29 & 96.7 & 29 & 96.7 & 1.00 \\
\hline $3^{\text {rd }}$ follow-up & 15 & 50.0 & 14 & 46.7 & 1.00 \\
\hline $4^{\text {th }}$ follow-up & 5 & 16.7 & 3 & 10.0 & 0.706 \\
\hline
\end{tabular}

\section{Nausea}

\begin{tabular}{lccccc}
\hline $1^{\text {st }}$ follow-up & 29 & 96.7 & 29 & 30.0 & 1.00 \\
\hline $2^{\text {nd }}$ follow-up & 9 & 30.0 & 4 & 13.3 & 0.117 \\
\hline $3^{\text {rd }}$ follow-up & 1 & 6.7 & 0 & 13.3 & 1.00 \\
\hline Vomiting & & & & & \\
\hline $1^{\text {st }}$ follow-up & 22 & 73.3 & 18 & 60.0 & 0.273 \\
\hline Leucopenia & & & & & \\
\hline $1^{\text {st }}$ follow-up & 13 & 43.3 & 5 & 16.7 & 0.024 \\
\hline $2^{\text {nd }}$ follow-up & 2 & 6.7 & 0 & 0.0 & 0.492 \\
\hline Enteritis & & & & &
\end{tabular}

\section{Enteritis}

\begin{tabular}{lccccc}
\hline $1^{\text {st }}$ follow-up & 15 & 50.0 & 14 & 46.7 & 0.769 \\
\hline $2^{\text {nd }}$ follow-up & 2 & 6.7 & 2 & 6.7 & 1.00 \\
\hline Dermatitis & & & & & \\
\hline $1^{\text {st }}$ follow-up & 16 & 53.3 & 7 & 23.3 & 0.017 \\
\hline $2^{\text {nd }}$ follow-up & 10 & 33.3 & 8 & 26.7 & 0.573 \\
\hline $3^{\text {rd }}$ follow-up & 1 & 3.3 & 2 & 6.7 & 1.00 \\
\hline $4^{\text {th }}$ follow-up & 0 & 0.0 & 1 & 3.3 & 1.00 \\
\hline${ }^{*}$ Followed by concurrent chemoradiotherapy &
\end{tabular}

Most common toxicities among both arm was haematological, skin toxicity, anorexia \& enteritis. Almost all patients in both arms had developed anorexia and in successive follow-up the numbers decreased in both arms. Almost similar trend was found regarding nausea. Patients had developed leucopenia more in arm A than arm B (5).In both arms, almost half of the patients (arm A (15), arm B (14)) developed enteritis.

Significantly more patients (16) developed dermatitis in arm A than arm B(7). 


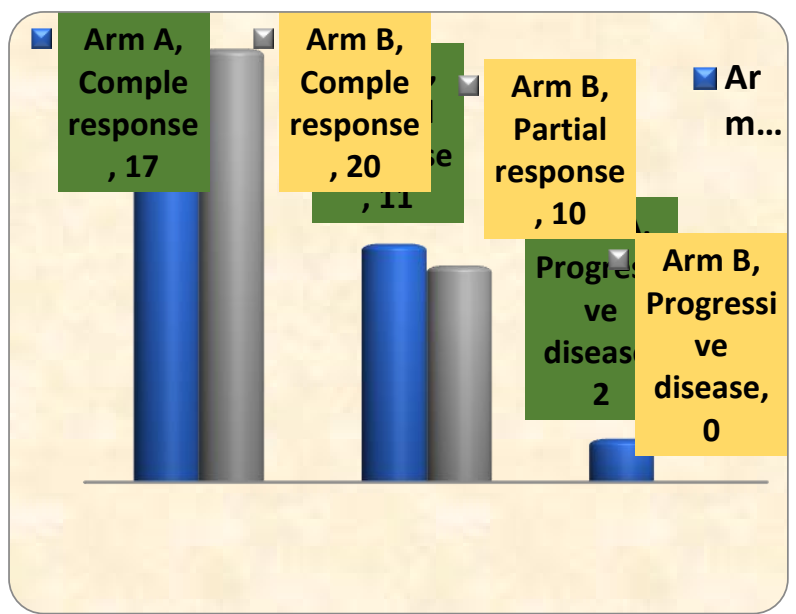

Figure: 1 Column showing distributions of the patients by post treatment response

Summary of post treatment responses is shown in the above figure. In arm A 17 patients (56.7\%) showed complete response where in arm B complete response was noticed in 20 patients (66.7\%); partial responses were $11(36.7 \%)$ and $10(33.3 \%)$ in the two arms respectively. Only two patients in arm A were found with progressive disease. No statistically significance was found between these two arms ( $p=0.526)$

\section{Discussion}

Cervical cancer is one of the commonest gynecological cancers among middle aged women.It is the second most common cancer in women and fifth most common malignancy worldwide. $^{20}$ Chemoradiotherapy has been the standard for treatment of advanced cervical cancer. $^{21-23}$ However, in a resource challenged country like Bangladesh providing all eligible cancer patients with timely radiotherapy is an unmet dream till today. Most of the patients have to wait in long queue to experience the first ever exposure of radiation. In this process the disease become deteriorates and the desired effects is not achieved. A recent meta-analysis involving 18 RCT showed that chemoradiotherapy has better 3year and 5-year survival rate compared to radiotherapy alone while the adverse effects were not statistically different ${ }^{24}$.
This current quasi-experimental study was carried out to compare the disease response, locoregional control and toxicities between induction chemotherapy followed by concurrent chemoradiation and concurrent chemoradiotherapy only. In this study 60 subjects were enrolled. Among 60 subjects 30 subjects were in Arm A who were treated inj. Cisplatin $\left(75 \mathrm{mg} / \mathrm{m}^{2}\right)$ D-1plus inj. 5-FU(1000mg/m²) D1-D3 every 21 day courses followed by concurrent chemoradiation 50 Gy in 25 fractions over 5 weeks with inj. cisplatin $40 \mathrm{mg} / \mathrm{m}^{2}$ weekly and 30 subjects in arm B who were treated with external beam radiotherapy 50 Gy in 25 fractions over 5 weeks with weekly inj. Cisplatin $40 \mathrm{mg} / \mathrm{m}^{2}$. All patients in both arm A and arm B were received brachytherapy after completion of EBRT. The findings of the study are discussed on basis of related previous studies concerning the objective of the study.

At the present study subjects were between stages IIB-IVA. It was found that most of the patients (arm A $50.0 \%$ vs. arm B $73.3 \%$ ) were in stage IIB. All patients in both arm A and arm B were treated with brachytherapy after completion of EBRT.

In arm A after completion of 2 cycle of induction chemotherapy patients were followed up before chemoradiation. Some of patients were down staged but not statistically significant.

Before starting of radiotherapy most of the patients in both arms had KPS 80. Starting from $2^{\text {nd }}$ follow up onwards number of KPS 100 increased in both arms successively. Most importantly, no difference was statistically significant.

Regarding toxicity at $1^{\text {st }}$ follow up considerable numbers of patients in both arms developed anaemia (arm A 21 and in arm B 17) and the number was higher in arm $A$ although the difference was statistically not significant. In successive follow-ups the numbers decreased in both arms. This trend was also evident in case of anorexia and nausea. At $1^{\text {st }}$ follow-up significantly more (13) patients had developed leucopenia in 
arm A than arm B (5). However the difference was not seen in next follow up.

In both arms, almost half of the patients developed enteritis at $1^{\text {st }}$ follow-up. In next two follow-ups the frequency of enteritis decreased dramatically in both arms. Significantly more patients (16) developed dermatitis in arm A than arm B (7) at $1^{\text {st }}$ follow-up. In successive follow-ups the number decreased in both arm but without any significant statistical difference. Tattersall et al. in their comparative study reported no significant difference of such toxicity across the arms. ${ }^{14}$

On per speculum, per vaginal and recto-vaginal examinations cervical growths, fornix involvement and parametrium involvements were examined. While before radiotherapy cervical growths were noted in most of the patients in both arms, in successive follow-ups gradually more patients were found with no growth in each arm. From $1^{\text {st }}$ to last follow ups gradually more patients were found with no fornix involvement. This statement was also applicable for parametrium involvement. However, the differences were not statistically significant $(\mathrm{p}>0.05)$.

On sonological findings before radiotherapy, cervical masses were present in most of the cases in both arms. At $4^{\text {th }}$ follow-up there were 21 $(70.0 \%) \& 23(76.7 \%)$ patients without any cervical growth in arm A and B respectively. However, no difference was statistically significant.

Regarding post treatment responses, in arm A 17 patients $(56.7 \%)$ showed complete response where in arm B complete response was noticed in 20 patients (66.7\%); partial responses were 11 $(36.7 \%)$ and $10(33.3 \%)$ in the two arms respectively. Only two patients in arm A were found with progressive disease. No statistically significance was found between these two arms $(p=0.526)$.

In a prospective randomized study by Dr. Vikas F et al compare the disease response, disease free survival, overall survival and toxicity profile to neoadjuvent chemotherapy followed by radiotherapy versus radiotherapy alone in locally advanced carcinoma cervix.In that study after 36 months of follow up clinical complete response was seen in $64.15 \%$ patients, partial response in $15.09 \%$ patients and $20.76 \%$ patients had died in CT-RT group. In the RT alone group $66.67 \%$ patients had clinical complete response, $14.82 \%$ patients had progressive disease and $18.51 \%$ patients had died. There were no significant difference in overall and disease free survival in the two groups. ${ }^{25}$

Chiara $\mathrm{S}$ et al in a randomized study comparing sequential chemotherapy plus radiotherapy versus radiotherapy alone in FIGO stage IIB-III cervical carcinoma stated that at a median follow up of 36 months survival and progression free survival were $83 \%$ and $72.4 \%$ in RT arm, $72 \%$ and $59.3 \%$ in $\mathrm{CT}+\mathrm{RT}$ arm, respectively. No significant difference was observed between two arms, neither in terms of objective response nor in terms of survival and PFS. Both treatments were generally well tolerated. ${ }^{26}$

Seoud $\mathrm{M}$ et al observed that stage and response to neoadjuvent chemotherapy had significant impact on overall survival for advanced carcinoma of the cervix, while age, tumor size and menopausal status did not influence survival. ${ }^{27}$

\section{Limitations of the Study}

Like other studies the present study was also not flawless. Although optimum care had been tried by the researcher in every steps of this study, still some limitations exist:

1. The time period was not enough to conduct a quality study.

2. Sample size was a major limitation in getting accurate clinical outcome.

3. The study was analyzed among the patients who attended NICRH only and therefore the entire situation of the patients with cervical carcinoma in the country have not provided.

\section{Conclusion}

To compare the disease response, locoregional control and toxicities between induction 
chemotherapy followed by concurrent chemoradiation and concurrent chemoradiotherapy only a quasi-experimental study was done at NICRH. Thirty patients were enrolled in each arm. From the present study it could be concluded that induction chemotherapy followed by concurrent chemoradiation was non inferior in terms of treatment response and toxicities than concurrent chemoradiotherapy only in treatment of locally advanced cervical carcinoma. Frequency of toxicities related to treatment was almost identical in two arms and no statistical difference was found.

\section{References}

1. Ferlay J, Soerjomataram I, Ervik M. GLOBOCAN 2012 v1.0, Cancer Incidence and Mortality Worldwide: IARC CancerBase No. 11 [Internet]. Lyon, France: International Agency for Research on Cancer; 2013 [cited 2017 Oct 22]. Available from: http://globocan.iarc.fr

2. American Cancer Society. Cancer Facts \& Figures-2015. Atlanta, Georgia: American Cancer Society; 2015.p.23.

3. National cancer control strategy \& plan of action 2009-2015. Dhaka: Ministry of Health \& Family Welfare; 2008. p. 3233. Available from: http://www.ban.searo.who.int/LinkFiles/P ublication_Cancer_Strategy.pdf .

4. Hussain S.M.A. Comprehensive update on cancer scenario Bangladesh. South Asian J Cancer. 2013;2:279-284.

5. Cancer registry report 2008-2010;National institute of cancer research \& hospital; Dec 2013;3-15,32.

6. Bosch Fx, de sanjose S. Human Papilloma virus \& cervical cancer- Burden \& Assessment of casualty. J Natt Cancer Inst Monegr 2003; 31: 3-13.

7. Vincent T. Devita VT, Lawrence TS, Rosenberg SA. Cancer Principles \& Practice of Oncology. 10 ${ }^{\text {th }}$ ed. Philadelphia: Wolterskluwer Health; 2015.
8. Halperin EC, Wager DE, Perez CA, Brady LW. Perez \& Brady's Principles \& Practice of radiation Oncology. $6^{\text {th }}$ ed. Philadelphia: Lippncott Williams \& Wilkins; 2013.

9. Pecoreli S., Zigliani L., Odeinio F. Revised FIGO staging for carcinoma of the cervix. Int J GynaecolObstet 2009; 105: 103-104.

10. Cervical cancer: Survival rates by stage [Internet]. Atlanta: American Cancer Society; 2017 [cited on 2017 Oct 5]. Available from: http:// www. cancer.org/cancer/cervical cancer/ detailed guide/ cervical cancer survival

11. Uma Singh, Neetu Ahirwar, Anju Kumari Rani et al. The efficacy and safety of neoadjuvent chemotherapy in the treatment of locally advanced carcinoma cervix. J Obset Gynaecol India. 2013 Aug; 63(4): 273-278.

12. Rajshree Dayanand Katke, Rewadkar Mahesh Shivhar, Priyanka Pagare. Role of neoadjuvant chemotherapy and radiotherapy in locally advanced carcinoma of the cervix. Clinical cancer invest J 2016;5:365-368.

13. Osman M. The role of neoadjuvant chemotherapy in the management of locally advanced cervical cancer: A systemic review. Oncol. Rev. 2014;28(2): 250.

14. Tattersall MH, Ramirez C, Coppleson M.A randomized trial comparing platinum-based chemotherapy followed by radiotherapy vs. radiotherapy alone in patients with locally advanced cervical cancer. Int $\mathrm{J}$ Gynecol Cancer. 1992;2(5):244-251.

15. Sundorf K, Trope CG, Hogberg $\mathrm{T}$ et al. Radiotherapy and neoadjuvent chemotherapy for cervical carcinoma. A randomized multicenter study of sequential cisplatin and 5-fluorouracil \& radiotherapy in advanced cervical 
carcinoma stage IIIB and IVA. Cancer 1996; 77: 2371-2378.

16. Kumar L, Kaushal M, Nandy BM, Biswal S, Kumar A, Singh KR et al. Chemotherapy Followed by Radiotherapy versus Radiotherapy Alone in Locally Advanced Cervical Cancer: A Randomized Study. Gynecologic Oncology 1994;54(3):307-315.

17. Silvana C, Milena B, Laura M, Paolo B, Riccardo R, Paola F et al. Randomized Study Comparing Chemotherapy Plus Radiotherapy Versus Radiotherapy Alone in FIGO Stage IIB-III Cervical Carcinoma. American Journal of Clinical Oncology 1994;25(3);211-217.

18. Chauvergne J, Rohart J, Henro JF et al. Randomized trial of initial chemotherapy in 151 locally advanced carcinoma of the cervix( T2b - N1, T3b, M0). Bull cancer. 1990; 77 (10):1007-24.

19. Duenas-Gonzalez A, Rivera L, Mota A et al.The advantages of concurrent chemoradiation after neoadjuvant chemotherapy for locally advanced cervical carcinoma. Arch Med Res.2002 Mar-Apr;33(2):201-2.

20. Loizzi V, Cormio G, Vicnio M, Selvaggi L. Neoadjuvant chemotherapy: an alternative option of treatment of locally advanced cervical cancer. Gynecol Obstet Invest 2008; 65: 96-103.

21. Whitney CW, Sause WB, Bundy N. Randomized comparison of fluorouracil plus cisplatin versus hydroxyurea as an adjunct to radiation therapy in stage IIBIVA carcinoma of the cervix with negative para-aortic lymph nodes: a gynecologic oncology group and Southwest oncology group study. Journal of Clinical Oncology 1999; 17(5):1339-48.

22. David H Moore (2005) Neoadjuvant chemotherapy for cervical cancer, Expert opinion on Pharmacotherapy, 4:6,859-857.
23. Mariateresa Lapresa, Gabriella Parma, Rosalba Portuesi \& Nioletta Colombo (2015) Neoadjuvant chemotherapy in cervical cancer: an update, Expert review of anticancer therapy, 15:10,1171-1181.

24. National Comprehensive Cancer Network: cervical cancer Version 2.2013, http://www.nccn.org/professionals/physici an gls/pdf/cervical.pdf.

25. Dr.Vikas Fotedar, Dr. Rajeeb K Seam, Dr.Manoj et al. Neoadjuvent chemotherapy followed by radiotherapy versus radiotherapy alone in locally advanced carcinoma cervix: A prospective randomized study.IOSR journal of dental and medical sciences. 2013;4(6);pp58-63.

26. Chiara S, Bruzzone M, Merlini L et al Randomized study comparing chemotherapy plus radiotherapy versus radiotherapy alone in FIGO stage IIB-III cervical carcinoma. Am j clin Oncol, 1994 Aug, 17(4):294-7.

27. Seoud M, Geara FB, Shamseddine A et al. Short duration neoadjuvant chemotherapy followed by radiotherapy for advanced carcinoma of the cervix: results and prognostic variables. Eur J Gynaecol Oncol. 2003;24(2): 163-8. 